3. Михеева O.В. Построение динамики влажности на темно-каштановых почвах Саратовского Заволжья с помощью модели SWAP // Вестник Саратовского госагроуниверситета им. Н.И. Вавилова. - 2007. № 3. - C. 72-73.

4. Михеева О.В. Совершенствование нормирования водосберегающих режимов орошения озимой пшеницы в условиях Саратовского Заволжья: автореф. дис. ... канд. техн. наук. - Саратов, 2005.

5. Михеева О.В. Совершенствование нормирования водосберегающих режимов орошения озимой пшеницы в условиях Саратовского Заволжья: дис. ... канд. техн. наук. - Саратов, 2005.

6. Портнов С.А., Михеева О.В., Михеев И.А. Автоматическая система полива декоративных растений в закрытом грунте на базе ARDUINO // Аграрный научный журнал. - 2018. - № 1. - С. 58-60.

7. Портнов С.А., Михеева О.В. К вопросу об автоматизированной системе полива декоративных растений в закрытом грунте // Аграрный научный журнал. - 2017. № 11. - C. 51-55.
Абдразаков Фярид Кинжаевич, $\partial-p$ техн. наук, проф., зав. кафедрой «Строительство, теплогазоснабжение и энергообеспечение», Саратовский государственный аграрный университет имени Н.И. Вавилова. Россия.

Михеева Ольга Валентиновна, канд. техн. наук, доцент кафедры «Строительство, теплогазоснабжение и энергообеспечение», Саратовский государственный аграрный университет имени Н.И. Вавилова. Россия.

Серебренников Федор Васильевич, $\partial-p$ техн. наук, проф. кафедры «Мелиорация, рекультивация и охрана земель», Саратовский государственный аграрный университет имени Н.И. Вавилова. Россия.

410056, г. Саратов, ул. Советская, 60.

Тел.: (8452) 74-96-53.

Михеев Иван Александрович, учащийся, Физико-технический лицей № 1 . Россия.

410012, г. Саратов, ул. Московская, 143.

Тел.: (8452) 26-42-35.

Ключевые слова: режим орошения; автоматизация системы полива; микроконтроллер.

\title{
TO THE QUESTION ABOUT THE AUTOMATION OF THE IRRIGATION AND WATERING SYSTEM IN AN OPEN GROUND
}

Abdrazakov Fyarid Kinzhaevich, Doctor of Technical Sciences, Professor, Head of the chair "Construction, Heat and Gas Supply and Energy Supply", Saratov State Agrarian University named after N.I. Vavilov. Russia.

Mikheyeva Olga Valentinovna, Candidate of Technical Sciences, Associate Professor of the chair "Construction, Heat and Gas Supply and Energy Supply", Saratov State Agrarian University named after N.I. Vavilov. Russia.

Serebrennikov Fedor Vasilievich, Doctor of Technical Sciences, Professor of the chair "Amelioration, Reclamation and Land Protection", Saratov State Agrarian University named after N.I. Vavilov. Russia.
Mikheev Ivan Alexandrovich, Student, Physico-Technical Lyceum No. 1. Russia.

Keywords: irrigation mode; irrigation system automation; microcontroller.

The article discusses the possibility of automating irrigation modes using ESP32 microcontrollers with an integrated radio module. The proposed model provides almost the full possibility of automation in setting the norms and timing of irrigation, taking into account the characteristics of the cultivated crop.

Удк $631.31(470.44)$

\section{РЕЗУЛЬТАТЫ ЭКСПЕРИМЕНТАЛЬНЫХ ИССЛЕДОВАНИЙ ПАХОТНОГО АГРЕГАТА МТЗ-82+ПБС-3М}

\section{БОЙкОВ Василий Михайлович, Саратовский государственный аграрный университет имени Н.И. Вавилова}

СТАРЦЕВ Сергей Викторович, Саратовский государственный аграрный университет имени Н.И. Вавилова

\author{
АГЕЕВ Алексей Владимирович, Саратовский государственный аграрный университет имени \\ Н.И. Вавилова
}

Представлено описание конструкиии и технической характеристики разработанного в Саратовском государственном аграрном университете лемешно-отвального плуга общего назначения ПБС-3М, агрегатируемого тракторами тягового класса 1,4. В результате экспериментальных исследований пахотного агрегата, состоящего из трактора МТЗ-82 и плуга ПБС-3М по стерневому фону поля с почвой низкой влажности и высокой твердости определены эксплуатационно-технологические показатели агрегата на основной отвальной обработке почвы. Исследования проведены в трех вариантах: в трехкорпусной комплектации плуга ПБС-3М, в комплектации с двумя корпусами, при снятом переднем корпусе; в комплектации с двумя корпусами, при снятом заднем корпусе. Приведены графические зависимости тягового сопротивления плуга и производтельности агрегата от скорости движения МТЗ-82+ПБС-3М.

Введение. Среди тракторов, используемых на пахотных операциях, применяются тракторы МТ3-80, МТ3-82, относящиеся по hоссийской классификации к тракторам тягового класса 1,4, мощность двигателя кото- рых не превышает 75кВт [2]. Однако работа таких тракторов с плугами ПЛН-3-35 имеет некоторые особенности. Так, колеса правой стороны трактора перемещаются в борозде, а левые колеса движутся по невспаханной части 
поля. В этом случае трактор движется с наклоном в сторону вспаханного поля и на правые бороздовые колеса распределяется большая часть массы трактора. Следовательно, левые и правые движители имеют разные сцепные свойства. В результате левые ведущие колеса буксуют больше, чем правые. Правые колеса, движущиеся по открытой борозде, производят дополнительное уплотнение дна борозды, что негативно сказывается на изнашивании колес трактора, проникновении влаги и урожайности культур [3]. Кроме того, работая в период вспашки по несколько часов в сутки, тракторист должен находиться в некомфортных условиях, постоянно уклоняясь в сторону, что влияет на его здоровье [5].

Учитывая недостатки известных пахотных агрегатов [1], в ФГБОУ ВО Саратовский ГАУ разработан лемешно-отвальный плуг общего назначения ПБС-3М для агрегатирования с тракторами мощностью $50 . .75$ кВт (рис. 1) [4]. Экспериментальный плуг ПБС-3М предназначендля основной обработкипочвыпод сельскохозяйственные культуры на глубину от 16 до 30 см, не засоренных камнями, плитняком и другими препятствиями, твердостью почвы до 4 МПа и влажностью до 30 \% [4]. Техническая характеристика плуга представлена в табл. 1.

Конструкция плуга содержит раму 1 (см. рис. 1), навесное устройство 2, опорные колеса

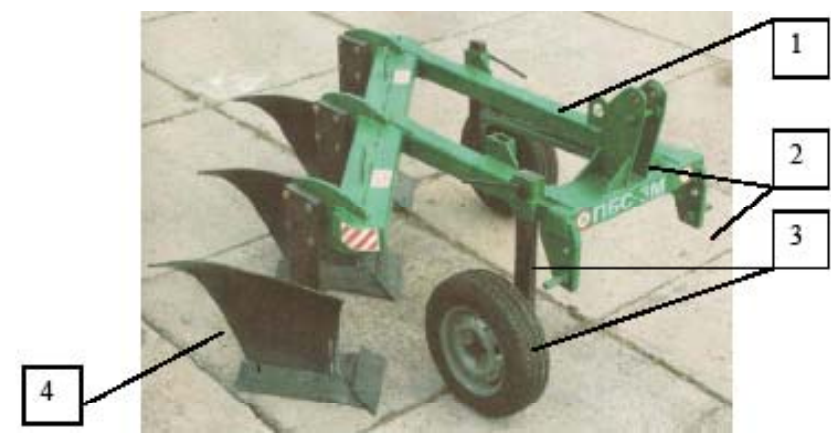

Рис. 1. Лемешно-отвальный плуг общего назначения ПБС-3М: 1 - рама; 2 - навесное устройство;

3 - опорные колеса с механизмами регулировки глубины; 4 - рабочие органы
3 с механизмами регулировки их положения относительно рамы (регулировка глубины вспашки) и рабочие органы 4, смонтированные на брусе рамы, который установлен под углом 45 к направлению движения.

Цель работы - определить эксплуатационнотехнологические показатели пахотного агрегата, скомплектованного из трактора МТ3-82 и плуга ПБС-3M.

Для достижения цели необходимо решить следующие задачи

1. Установить возможность работы пахотного агрегата МТ3-82+ПБС-3М в трех вариантах:

первый вариант - выполнение технологического процесса пахотным агрегатом с трактором тягового класса 1,4 в комплектации с трехкорпусным плугом ПБС-3М;

второй вариант - выполнение технологического процесса пахотным агрегатом с трактором тягового класса 1,4 с плугом ПБС-3М в комплектации с двумя корпусами, но при снятом переднем корпусе;

третий вариант - выполнение технологического процесса пахотным агрегатом с трактором тягового класса 1,4 с плугом ПБС-3М в комплектации с двумя корпусами, но при снятом заднем корпусе.

2. Определить эксплуатационно-технологические показатели пахотного агрегата в трех комплектациях.

Методика исследований. Для решения поставленных задач использовали разработанные методики эксплуатационно-технологической оценки пахотного агрегата согласно ГОСТ 24055-2016. Техника сельскохозяйственная. Методы эксплуатационно-технологической оценки и ГОСТ 33736-2016. Техника сельскохозяйственная. Машины для глубокой обработки почвы. Методы испытаний.

Экспериментальные исследования пахотного агрегата МТЗ-82+ПБС-3М проводили на поле после уборки озимой пшеницы. Рельеф

Таблица 1

Техническая характеристика плуга общего назначения

\begin{tabular}{|l|c|}
\hline \multicolumn{1}{|c|}{ Показатель } & 3начение \\
\hline Тип плуга & Навесной \\
\hline Ширина захвата (конструктивная), м & 1,2 \\
в комплектации с двумя корпусами & 1,8 \\
в комплектации с тремя корпусами & $2240 \times 1800 \times 1290$ \\
\hline Габаритные размеры, мм: длина × ширина × высота & 500 \\
\hline Дорожный просвет, мм & 560 \\
\hline Масса плуга, кг & $0-30$ \\
\hline Пределы регулирования рабочих органов по глубине, см & $2-3$ \\
\hline Количество рабочих органов, шт. & 620 \\
\hline Рабочая ширина захвата корпуса, мм & 780 \\
\hline Расстояние от опорной плоскости корпусов до нижней плоскости рамы, мм & 840 \\
\hline Расстояние между рабочими органами, мм & 40 \\
\hline Ширина захвата правого лемеха, мм & 20 \\
\hline Ширина захвата левого лемеха, мм & \\
\hline
\end{tabular}


полей был ровный, микрорельеф средневыраженный. Тип почв и гранулометрический состав - чернозем обыкновенный среднесуглинистый, не засоренный плитняком и камнями. Условия исследований характеризовались как засушливые, влажность почвы в слое $0 . .30$ см равнялась $16,7-23,1 \%$. Твердость почвы в слое 0-20 см составляла 2,7...3,7 МПа, но в нижнем слое от 20 до 30 см достигала 5,7 МПа, что указывает на достаточно тяжелые условия исследований. Высота растительных и пожнивных остатков на обрабатываемом поле со стерней озимой пшеницы составляла в среднем 18,3 см. Масса растительных и пожнивных остатков на 1 м $^{2}$ - 415,0 г. Предшествующая обработка почвы на поле проводилась.

Результаты исследований. При обработке поля плугом ПБС-3М с тремя рабочими органами конструктивной шириной захвата 1,8 м было установлено, что агрегат с трактором МТ3-82 с колесной формулой 4К4 движется всеми колесами по необработанному стерневому фону поля (рис. 2, a) и устойчиво выполняет технологический процесс.

В результате снятия одного корпуса спереди плуга ПБС-3М (рис. 2, б) конструктивная ширина захвата уменьшилась на $0,6 \mathrm{M}$. Навеска плуга так же, как и в первом варианте, осуществлялась по трехточечной схеме. Выполнение технологического процесса пахотным агрегатом с трактором тягового класса 1,4 с плугом в комплектации с двумя корпусами полностью обеспечивалось. Сохранялась заделка открытой борозды, трактор всеми колесами двигался по поверхности необработанного поля.

В исследованиях третьего варианта с плуга ПБС-3М был снят один корпус сзади плуга (рис. 2 , в). Конструктивная ширина захвата плуга, как и во втором варианте, составила 1,2 м. Агрегат

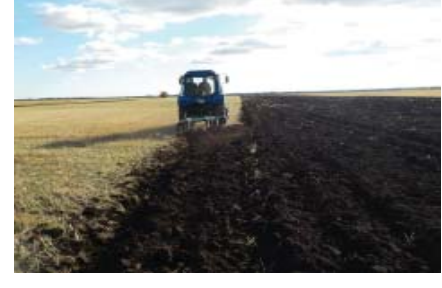

$a$

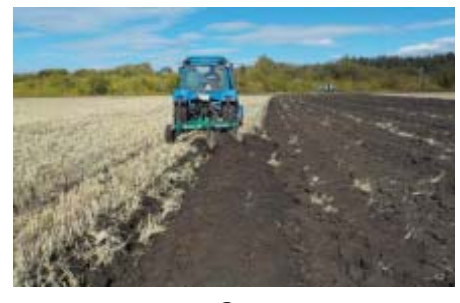

$\boldsymbol{B}$

Рис. 2. Пахотный агрегат МТ3-82+ПБС-3М в работе: $а$ - с тремя корпусами; б - с двумя корпусами, при снятом переднем корпусе; в - сдвумя корпусами, при снятом заднем корпусе устойчиво выполнял технологический процесс основной отвальной обработки почвы, при этом трактор всеми колесами находился на поверхности необработанного поля.

Согласно проведенным исследованиям [5], профиль обработанного поля на рассматриваемом участке был равномерным. Величина вспушенности обрабатываемого пласта почвы (расстояние между дневной поверхностью необработанного поля и дневной поверхностью обработанного поля) в среднем составляла 9 см. Стерня и растительные остатки были заделаны в пахотный слой почвы и находились на расстоянии 12-13 см от дневной поверхности обработанного поля. При этом стерня на этой глубине находилась в наклоненном и горизонтальном положении. Ниже горизонта расположения стерни и растительных остатков пласт почвы находился в раскрошенном состоянии. Так как трактор МТ3-82 всеми колесами и во всех вариантах двигался по необработанному полю рядом с открытой бороздой, дополнительного уплотнения дна открытой борозды не происходило.

Исследования качества крошения почвы низкой влажности и высокой твердости показали, что количество фракций почвы размерами менее 50 мм, образующихся при работе трехкорпусного плуга на глубине пахоты 16 см и скоростях движения агрегата 2,77 и 3,11 м/с, составляет 86,2 и $88,8 \%$, что соответствовало агротехническим требованиям (не менее 75 \%). Степень крошения почвы в таких же условиях почвы по влажности и твердости, при работе агрегата МТ3-82+ПБС-3М в комплектации с двумя корпусами без переднего корпуса, на глубине пахоты 25 см и скоростях движения агрегата 2,0 и $2,27 \mathrm{M} /$ с составила $97,8-97,3 \%$. При работе МТЗ-82+ПБС-3М в комплектации с двумя кор-

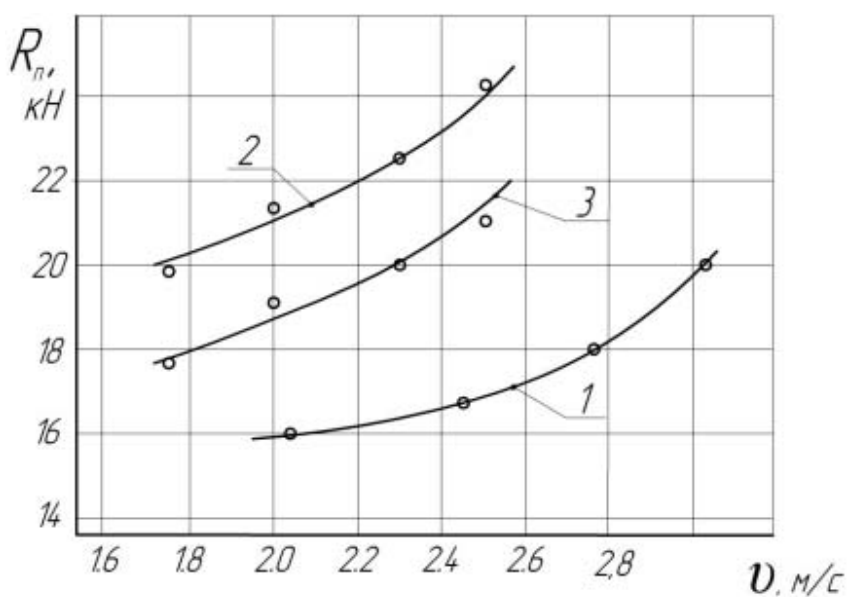

Рис. 3. Зависимость тягового сопротивления $R_{n}$ плуга ПБС-ЗМ от скорости движения ч агрегата: 1 - в комплектации с тремя корпусами, глубина обработки почвы 16 см; 2 - сдвумя корпусами без переднего корпуса, глубина обработки почвы 25 см; 3 - сдвум корпусами без заднего корпуса, глубина обработки почвы 25 см 
пусами без заднего корпуса на глубине пахоты 25 см при скорости движения агрегата 2,08 и $2,58 \mathrm{~m} / \mathrm{c}$, степень крошения почвы составила $75,3-86,4 \%$.

На рис. 3 представлены зависимости тягового сопротивления плуга ПБС-3М в трех комплектациях от скорости движения агрегата на глубине обработки 16 и 25 см.

Анализ зависимостей (см. рис. 3) показывает, что тяговое сопротивление во всех вариантах изменяется по нелинейной закономерности. С увеличением скорости движения агрегата МТЗ-82+ПБС-3М и глубины обработки почвы интенсивность тягового сопротивления плуга возрастает. При исследовании второго и третьего вариантов установлено, что при снятом заднем корпусе тяговое сопротивление плуга ПБС-3М на 9,2-12,9 \% ниже, чем тяговое сопротивление плуга ПБС-3М при снятом переднем корпусе.

На рис. 4 представлены зависимости часовой производительности пахотных агрегатов МТЗ-82+ПБС-3М в двух- и трехкорпусной комплектации от скорости движения агрегата.

Анализ зависимостей (см. рис. 4) показывает, что часовая производительность возрастает нелинейно в функции скорости движения. Производительность пахотного агрегата МТЗ-82+ПБС-3М с тремя корпусами при скорости 3,0 м/с и глубине обработки почвы $16 \mathrm{~cm}$ достигает 1,8 га/ч. Производительность МТ3$82+$ ПБ-3М с двумя корпусами при снятом первом корпусе при скорости 2,5 м/с и глубине обработки почвы 25 см составляет 1,18 га/ч. Производительность МТЗ-82+ПБС-3М с двумя корпусами при снятом заднем корпусе при той же скорости $2,5 \mathrm{~m} / \mathrm{c}$ и глубине обработки почвы 25 см достигает 1,1 га/ч. На снижение производительности агрегата повлияло уменьшение рабочей ширины захвата, при снятом заднем корпусе плуга она составила 1,14 м, при снятом переднем корпусе - 1,3 м.

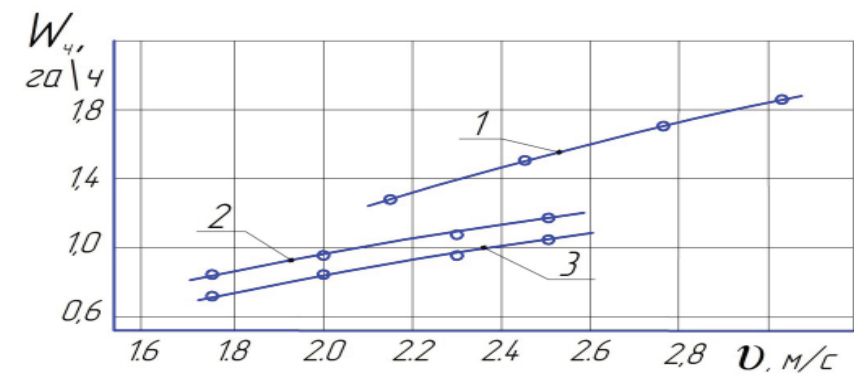

Рис. 4. Зависимость часовой производительности $W_{\text {ч }}$ пахотных агрегатов МТЗ-82+ПБС-3М от скорости движения ч агрегата:

1 - в комплектации с тремя корпусами, глубина обработки почвы 16 см; 2 - сдвумя корпусами без переднего корпуса, глубина обработки почвы 25 см; 3 - сдумя корпусами без заднего корпуса, глубина обработки почвы 25 см
Заключение. Для основной отвальной обработки почвы используются тракторы тягового класса 1,4 типа МТ3-82 и известные плуги ПЛН-3-35. Однако такие пахотные агрегаты имеют низкие эксплуатационно-технологические показатели.

В ФГБОУ ВО Саратовский ГАУ разработан лемешно-отвальный плуг общего назначения ПБС-3М для агрегатирования с тракторами МТ3-82. Трактор МТЗ-82 с плугом ПБС-3М может работать в трех- и двухкорпусной комплектации. Причем с двумя корпусами плуг может работать при снятом переднем и при снятом заднем корпусах. Во всех трех вариантах агрегат МТ3-82+ПБС-3М всеми колесами двигается по необработанному стерневому фону поля рядом с открытой бороздой.

Агротехническая оценка показала, что пахотный агрегат МТЗ-82+ПБС-3М в комплектации с тремя и двумя корпусами выполняет технологический процесс основной отвальной обработки почвы, полностью удовлетворяющей агротехническим требованиям.

Конструкция корпуса плуга ПБС-3М и отсутствие полевых досок на корпусе повлияли на снижение его тягового сопротивления и повышение производительности пахотного агрегата. Производительность МТЗ-82+ПБС-3М с тремя корпусами при скорости 3,0 м/с и глубине обработки почвы 16 см составила 1,8 га/ч (см. рис. 4, поз. 1). На производительность агрегата МТЗ-82+ПБС-3М с двумя корпусами, влияет условие расстановки корпусов на раме плуга. При снятии заднего корпуса рабочая ширина плуга захвата составила 1,14 м, а при снятии переднего корпуса - 1,3 м, при этом изменение рабочей ширины захвата влияет на рост 9,2-12,9 \% тягового сопротивления плуга ПБС-3М (см. рис. 3, поз. 2 и 3).

\section{СПИСОК ЛИТЕРАТУРЫ}

1. Агеев А.В., Афонин А.Е. Технические характеристики плугов, агрегатируемых тракторами мощностью до 75 кВт // Роль и значение науки и техники для развития современного общества: сб. статей Междунар. науч.-практ. конф. - Ч. 1. - Уфа: Омега Сайнс, 2018. C. 27-32.

2. ГОСТ 27021-86. Тракторы сельскохозяйственные и лесохозяйственные. Тяговые классы. - М., 1986.

3. Погодин Н.Н., Кучко В.В. Влияние уплотнения почвы на урожайность сельскохозяйственных культур // Агропанорама. - 2008. - № 4(68). - С. 28-31.

4. Протокол № 08-66П-2018 приемочных испытаний плуга навесного ПБС-3М. - Кинель, 2018. - 35 с.

5. Регулировка пахотных агрегатов и проведение пахоты: альбом-справочник. - М.: Россельхозиздат, 1975. - 143 c.

Бойков Василий Михайлович, $\partial-p$ техн. наук, проф. кафедры «Техническое обеспечение АПК», Саратовский государственный аграрный университет имени Н.И. Вавилова. Россия. 
Старцев Сергей Викторович, $\partial-p$ техн. наук, проф. кафедры «Техническое обеспечение АПК», Саратовский государственный аграрный университет имени Н.И. Вавилова. Россия.

Агеев Алексей Владимирович, аспирант кафедры «Техническое обеспечение АПК», Саратовс- кий государственный аграрный университет имени Н.И. Вавилова. Россия

410056, г. Саратов, ул. Советская, 60.

Тел.: (8452) 74-96-53.

Ключевые слова: пахотный агрегат; конструкиця; трактор; плуг.

\section{THE RESULTS OF EXPERIMENTAL STUDIES OF ARABLE UNIT MTZ-82+PBS-3M}

Boykov Vasiliy Mihaylovich, Doctor of Technical Sciences, Professor of the chair "Technical Equipment of AIC", Saratov State Agrarian University named after N.I. Vavilov. Russia.

Startsev Sergey Viktorovich, Doctor of Technical Sciences, Professor of the chair "Technical Equipment of AIC", Saratov State Agrarian University named after N.I. Vavilov. Russia.

Ageev Aleksey Vladimirovich, Post-graduate Student of the chair "Technical Equipment of AIC", Saratov State Agrarian University named after N.I. Vavilov. Russia.

Keywords: arable unit; construction; tractor; plough.
It is given the description of the design and specifications developed in Saratov State Agrarian University plow-blade grader of general purpose $P B S-3 M$ aggregated with tractors of traction class 1.4. In the result of experimental researches of the arable unit consisting of the MTZ-82 tractor and the plow PBS-3M on a stubble background of the field with soil of low humidity and high hardness operational and technological indicators of the unit on the main dump processing of the soil are defined. Studies were conducted in three ways: plough PBS-3M fitted with three frames, fitted with two frames, with removed front frame; fitted with two frames, removed the rear frame. The graphical dependences of the plow traction resistance and the unit performance on the speed of MTZ-82+PBS-3M are presented.

удк 631.3.004.67

\section{РАСЧЕТНАЯ ОЦЕНКА ПРИМЕНЕНИЯ РАСПЛАВОВ ЭЛЕКТРОЛИТА ПРИ УПРОЧНЕНИИ ВОССТАНОВЛЕННЫХ РАБОЧИХ ОРГАНОВ ПОЧВООБРАБАТЫВАЮЩИХ И ПОСЕВНЫХ АГРЕГАТОВ}

БУйлов Валерий Николаевич, Саратовский государственный аграрный университет имени Н.И. Вавилова

Обоснована необходимость разработки математической модели расчетно-теоретической проверки применимости различных составов электролита для борирования. Предложены формулы и системы уравнений, представляющие собой такую математическую модель. Результаты расчетов по этим формулам позволили оценить несколько составов электролита и установить предпочтительный вариант для борирования при упрочнении восстановленных рабочих органов почвообрабатывающих и посевных агрегатов.

Введение. При принятии технологических решений необходимо провести их теоретическое обоснование [11]. Поэтому требуется математическое моделирование основных технологических операций упрочнения дополнительной детали при восстановлении работоспособности рабочих органов почвообрабатывающих и посевных агрегатов с повышением их ресурса. В результате научных и технологических исследований был разработан способ электролизного борирования этих деталей.

Математическое моделирование движения ионов в расплаве электролита требует учета процессов конвекции, миграции и диффузии. Действующая на ион сила электрического поля заставляет его двигаться с определенной скоростью, которая определяется его подвижностью. Диффузия ионов выражается через градиент концентрации $[1,2]$.

Методика исследований. Перемещение ионов, обеспечивающееся движением расплавленной среды, является его конвективной составляющей. Поэтому поток $i$-х ионов, перемещающихся в движущейся расплавленной среде $[1,10]$, описывается системой $(1)$ :

$$
J_{i}=C \bar{V}-D_{i} g r a d C_{i}+\frac{C_{i} D_{i} Z_{z}^{i} F E_{\text {эп }}}{R_{y} T},
$$

где $C_{i}$ - концентрация $i$-го иона, моль/л; $\bar{V}-$ поле скоростей течения расплавленной сплошной среды, м/с; $D_{i}-$ коэффициент диффузии $i$-го иона, $\mathrm{M}^{2} / \mathrm{c} ; Z_{i}^{z}$ - заряд $i$-го иона; $F$ - постоянная Фарадея, Кл/моль; $\mathrm{E}_{\text {эп }}$ - напряженность элект- 